\title{
What kind of Thai Patients factors to Request Prescribing from Physicians
}

\author{
Dr. Chulaporn Kobjaiklang \\ Rattana Bundit University
}

\begin{abstract}
This study investigates the Thai healthcare system in regard to the factors influencing the practice of prescribing in the pharmaceutical industry. The healthcare system in Thailand is shifting towards one in which informed patients make their own medical decisions. The sudden increase of channels directed to both patients and medical practitioners makes it very difficult for pharmaceutical companies to control the value of information related to the practice of prescribing.Accordingly, the purpose of this study was to examine the influence of patients influencing factors several marketing channels and their influence on the practice of prescribing. The findings of the study indicated that the study is useful in understanding the variables that influence prescription patterns of patients in the Thai healthcare system. The patients, there was no significant correlation between the patients' experience with the medication and their intent to request the same medication. Understanding the marketing channels and their relationship with prescribing practices has implications for the development of marketing strategies in the pharmaceutical industry.
\end{abstract}

Keywords: Thai healthcare, prescribing, pharmaceutical industry, patients

\section{INTRODUCTION}

The Prescription drug industry is "unique". The marketing strategies employed in the pharmaceutical industry sharply contrast with those typically adopted in other markets. .In the past of Thai healthcare system the decision marker was physicians who have chooses among a range of drug alternatives, but the patients who takes the medications. For now the healthcare system in Thailand is shifting towards one in which informed patients make own medical decisions. The patient's role has increased and very important facts are changing the nature of the industry. This increase of channels directed to both patients and physicians makes together decisions it very difficult for pharmaceutical companies to control the quality of information driving purchase. Therefore, it is harder to define the customer in transactions. The present study has the purposes: investigates the Thai healthcare system in regard to the factors influencing the practice of prescribing in the pharmaceutical industry.

Thailand is dependent on imported pharmaceutical and raw materials to locally manufacture pharmaceutical to meet the domestic demand. The Thai government in aware of the country's dependency and is addressing the pharmaceutical industry hoping that promotion privileges through the Board of Investment in Thailand (BOI) will develop the pharmaceutical industry. It hoped that Thailand will modernize and effectively enforce its legislation facilitating the development of the pharmaceutical industry, among other by reinforcement of the intellectual property rights. Additionally it is the hope that the controversial and not yet signed Free Trade Agreement with America will develop the Thai medicine market. The increase demand for 
pharmaceutical is partly caused by an increasing number of expatriates, health tourists visiting Thailand and changes lifestyles among the Thai population.

First, people are living longer and healthier lives. This is influencing the prescription industry. According to forecasts the Thai population is ageing and it is expected that number of persons above 60 years will increase during the future.

Second, Direct-to-Consumer (DTC) advertising is now achieving a real presence in the media; it is worth paying attention to the impact of various media on these important health care decision makers.

Third, which demographic groups are most likely to be to influence prescription habits? The Thai pharmaceutical market relatively significant long-term potential, given the country's growing population, healthcare sector modernization and economic development.

Fourth, the price of pharmaceutical products, prescription drug spending is rising dramatically as the percentage of overall healthcare cost. Pricing and reimbursement policies have been-and continue to be-a considerable cause of friction between the government and the international drug industry. Public sector drug prices are strictly controlled by the government, which maintain a list of essential drugs the National List of Essential Drugs (NLED) for reimbursement purposes. The list contains few higher-cost foreign medicines, with producers instead seeking listing on individual hospital formularies.

Fifth, managed care plans. Thailand had recovered from its financial crisis and most economic indicators were approaching or had surpassed pre-crisis levels.

\section{OVERVIEW OF PHARMACEUTICAL INDUSTRY}

The pharmaceutical business is all about prescriptions (Smith, 2003, p. 153). Without prescriptions written by physicians there is no business and without patients there are no customers for pharmaceutical products. The pharmaceutical industry concentrates its efforts on marketing strategies dedicated to physicians. Today, the patient's role has increased and very important facts are changing the nature of the industry. There are six factors that contribute to the change in prescription patterns (Nagiel, 1998).

Today medical treatment not only cure disease, but furthermore, they enhance the quality of life. Problem statement: In Thailand, pharmaceuticals are a major feature of the health system: up to $60 \%$ of the population's health expenditure goes on drugs. Moreover, these drugs are mainly distributed through non-institutional outlets and by non-qualified personnel. While it is quite possible that it is legally required for a pharmacy to be operated by a qualified pharmacist, this is certainly not the case. Various pharmacies employ different standards. Some are clearly run by pharmacists themselves, some are run by employees with a pharmacist somewhere in the background, some are run by people who do not have a clue about medicine. We do not even know whether one can ask specifically for a prescription to be used at an outside pharmacy or none. In any case, quite clearly the pharmacies at major hospitals charge more for drugs than the outside pharmacies. Thailand would gain by investing in areas where it is relatively competent and where benefits are likely to be obtained for society as a whole. At the same time, key players in the health sector have to prepare themselves for a new era of competition. 


\section{Theoretical Framework}

\section{RESEARCH DESIGN AND METHODS}

The purpose of this study was to examine the patients influencing factors of several marketing channels and their influence on the practice of prescribing

First, the specific goal is to understand the extent to which patient's health status may impact their purchasing behavior. The second goal is to examine physician attitudes regarding patients' request for medication and what factors are influencing such behavior. The prescribing study involves 4 patient constructs or factors. These factors will be examined to better understand patient's behavior and their degree of involvement with branded medications. There are direct and indirect factors related the patient's intent to prescribe. Direct factors are price of the medication and the managed care formularies are defined as those factors that directly affect patient's intent purchase. Indirect factors direct-to-customer (DTC) may or may not affect patient's purchasing intention on the same level of significance as direct factors. The patient theoretical framework involves patient's health status related to four factors:

\section{Direct Factors}

1. Price of pharmaceutical products.

2. Managed care.

3. Behavioral Factors: Familiarity and loyalty.

\section{Indirect Factor}

4. Direct to Consumer Advertising.

\section{Prescribing Model Patient}

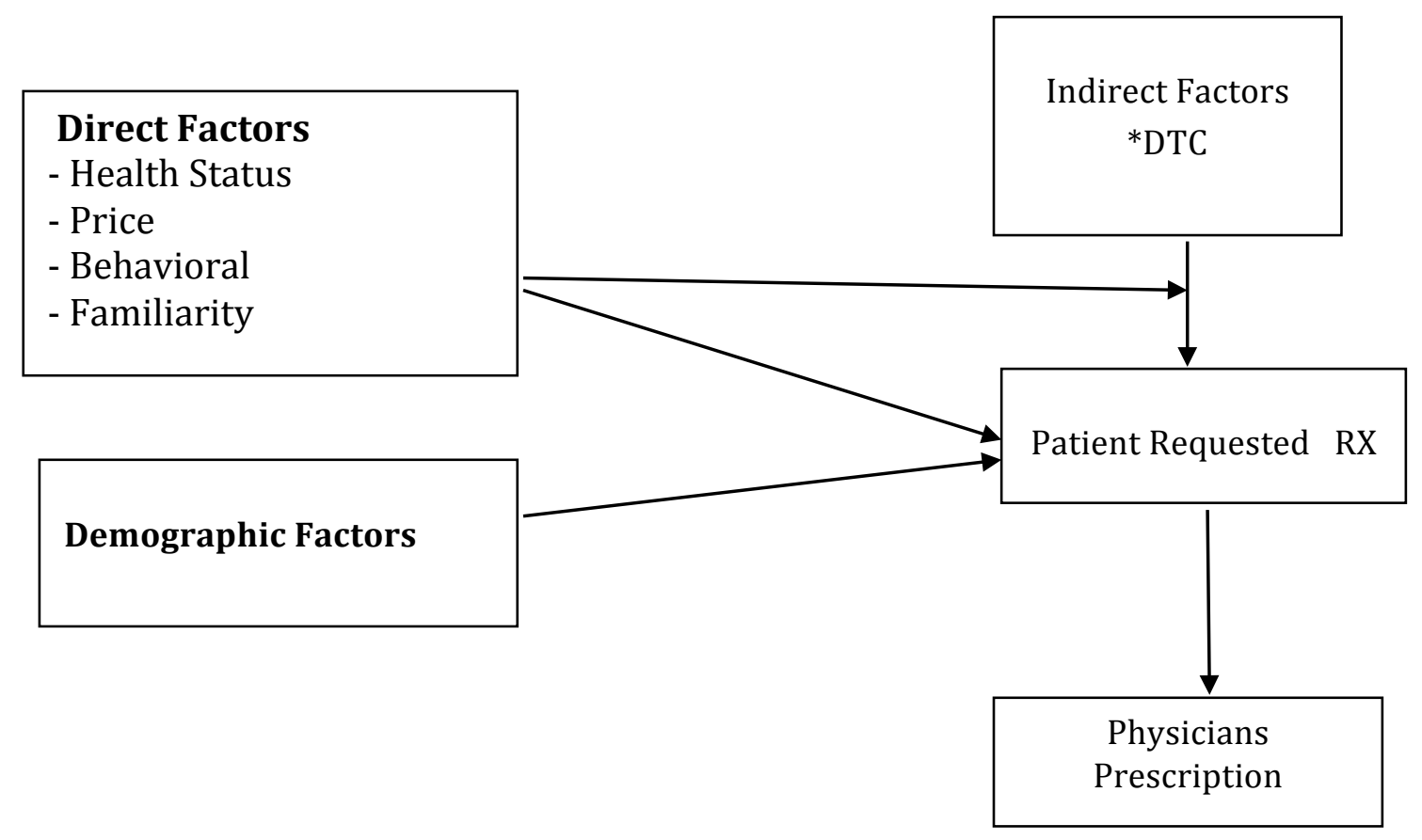

Figure1. The framework for explain the associations between health status, price, behavioral and familiarity direct factors and indirect factor DTC included demographic factors patient intent to request prescript from their physicians. 
The questions were design to discover patient's factors to request medications. The questions were answered using a 7 point Likert scale (Osgood et al., 1957, p. 348). Six item on the patient's survey were examined: (1) price (2) loyalty (3) direct-to-consumer advertising (4) managed care (5) severity of health and (6) experience with medication. A 7 point Likert scale was used to investigate the ten items that affect patient's health. A total score for the ten items will be used to distinguish the patient's quality of life (Osgoog et al., 1957).

For the patients, a limiting factor is that this study in aimed to investigate the relationship between health statuses and purchasing behavior, it does not study in detail what health condition specifically is affecting this behavior.

\section{Research Questions}

This research centers on decision makers;

1. What factors are patients influencing prescribing from their physicians?

2. What factors are influencing patients to request pharmaceutical products to physicians?

\section{Hypothesis}

Hypothesis 1: Is there a relationship between the severity of patient's health and the intent to request medication?

H1: There is no significant or negative relationship between the severity of health status condition and the intent to request prescription from prescribers.

NH 1: There is a significant or positive relationship between the severity of health status condition and the intent to request prescription from prescribers.

Hypothesis 2: Is there a relationship between the direct-to-consumer advertising and patient intent to request moderated by patients' health status condition?

H2: The severity of health status condition has no significant moderating effect on the relationship between the Direct-to-consumer advertising and intent to request prescription drugs.

NH2: The severity of health status condition has a significant moderating effect on the relationship between the Direct-to-consumer advertising and intent to request prescription drugs.

Hypothesis 3: Is there a relationship between price and intent to request medication moderated by health status condition?

H3: The severity of patient health status has no significant moderating effect on the relationship between price and the intent to request prescription drugs.

NH3: The severity of patient health status has a significant moderating effect on the relationship between price and the intent to request prescription drugs.

Hypothesis 4: Is there a relationship between behavioral factors such as familiarity, on the patients' intent to request the same drugs?

H4: There is no relationship between familiarity and the intent to request prescription drugs.

NH4: There is a significant relationship between familiarity and the intent to request prescription drugs. 
Hypothesis 5: To what extent are demographic factors related to the intent to request drugs among patients? Are educate patients behaving different than non-educate patients?

H5: There is no significant relationship between demographic factors and intent to request medication.

NH5: There is a significant relationship between demographic factors and intent to request medication.

Hypothesis 6: Is there a direct relationship between direct-to-consumer advertising and patients' request prescription?

H6: There is no significant relationship between direct-to-consumer advertising and the patient's intent to request prescription drugs.

NH6: There is a significant relationship between direct-to-consumer advertising and the patient's intent to request prescription drugs.

Hypothesis 7: Is there a direct relationship the formulary status of the medication and the patients' request for prescription?

H7: There is no significant relationship between the formulary status of the medication and the patient's intent to request prescription drugs.

NH7: There is a significant relationship between the formulary status of the medication and the patient's intent to request prescription drugs.

\section{RESULT}

Patient demographic characteristics for gender, approximate age, education level, income employment and work type. The patients response rate was $81.3 \%$ or 230 surveys, the final sample consisted of 187 complete surveys. The sample $(n=187)$ was comprised of $81.3 \%$ males $(n=117)$ and $37.4 \%$ females $(n=70)$.

The study was tested using patient data. The response rate was approximately $81.3 \%$ the final survey included $\mathrm{n}=187$ patients. Patient constructs includes the price of medication, formulary, direct-to-consumer, and familiarity with the medication. Thirty six point nine of the patients were between 20-29 years of age, 13.9\% of them were between 30-39 years of ages, $30.5 \%$ of them were between $40-49$ years of ages, $15.5 \%$ of them were between $50-59$ years of age and $3.2 \%$ of them were 60 years or older. The majority of patients had $32.6 \%$ completed a Bachelor degree educational levels, 5.9\% had not completed high school, $7 \%$ had completed high school, $22.5 \%$ had some college or associate degree, $6.4 \%$ had completed master degree or higher educational levels and $25.7 \%$ had completed other educational levels. The patients' income ranged from less than 10,000 baht to 50,000 or more. Sixty six point eight percent of the patients' income ranged less than 10,000 baht, $21.9 \%$ of patients' incomes ranged between 10,000 to 25,000 baht, $8 \%$ of patients' income ranged between 25,000 to $35,000 \mathrm{baht}, 1.1 \%$ of patients' income ranged between 35,000 to 50,000 baht and $2.1 \%$ of patients' income higher than 50,000 baht per month. The majority of patients work were employee, $8.6 \%$ of patients work were government employee, $8.6 \%$ of patients work were own business, $11.8 \%$ of patients work were state enterprises and $49.7 \%$ of patients work were other work. 


\section{Factor Analysis and Reliability of Measurement Instruments}

The analysis involves factor analysis of each of the multi-item scales. Each of the scales yielded one component with an Eigenvalue that was greater than one. This result confirms that the multi-item scale were one-dimensional. Then, reliability analysis was performed on each of the measurement scales. A coefficient alpha (Combat alpha) was calculated for each multi-item scale to assess the internal consistency. The item analysis provides information about how well each individual item is related to others within the group. A strict adherence to the reliability standard of .70 was followed in this analysis. Many respondents commented about the appropriateness of the items in the survey.

\section{Hypothesis Testing-Patients}

A one sample test of the mean was used to compare the sample mean to the neutral point of the scale. Survey responses were coded on a 7-point Likert scale, values ranged from "1" representing "not at all or important" or "strongly disagree" to "7" representing "extremely important" or "strongly agree" (Osgood et al., 1957).

Each scale mean score was compared to what the total would be if the respondent had neutral responses ( 4 of 7 ) termed the test value using a one tail difference of means test. The null hypothesis in each case was that the mean was not rejected, then the patient was deemed not to support that mode of influence. The normality of the distribution was tested using a normal probability plot. An inspection did not reveal any deviation from normality.

\section{Hypothesis Finding-Patients}

H1: There is a significant positive relationship between the severity of health status condition and the intent to request prescription from prescribers.

The spearman correlation coefficient was utilized in hypothesis 1 . The correlation coefficient was not statistically significant $=.97$ and $\mathrm{p}=.76$.

H2: There severity of health status condition has a significant moderating effect on the relationship between DTC and intent to request prescription drugs.

To test hypothesis 2, the intent to request medications was correlated on health status, DTC and an interaction between total health and DTC.

H3: There severity of health status condition has a significant moderating effect on the relationship between price and intent to request prescription drugs.

Correlation analysis was used to test this hypothesis. The intent to request medication was correlated by health status, price of the medication and the interaction between total health and price. 
Table 1-t-test and One-Sample Statistics-Patients

$\mathbf{n}=\mathbf{1 8 7}$

\begin{tabular}{|c|c|c|c|c|c|c|c|}
\hline Sum of item & Minimum & Maximum & Neutral point & $\begin{array}{l}\text { Mean } \\
\text { Deviat }\end{array}$ & Std. & $\begin{array}{c}\mathrm{t} \\
\text { value }\end{array}$ & $\mathrm{p}$ \\
\hline DTC & 1 & 7 & 4 & 4.64 & 1.322 & 1.648 & 0.101 \\
\hline $\begin{array}{l}\text { Managed care } \\
\text { Familiarity }\end{array}$ & 1 & 7 & 4 & 5.33 & 1.055 & 69.025 & 0.000 \\
\hline With medication & 1 & 7 & 4 & 5.09 & 1.009 & 68.980 & 0.000 \\
\hline
\end{tabular}

\section{Note. From Statistical analysis}

H4: There is a significant relationship between familiarity with the medication and intent to request prescription drugs.

The meaning of the word relationship in this context is that there is an agreement with a questionnaire statement rather than a correlation. A sample mean test was utilized to test hypothesis 4 . The majority of responses were high the mean, the mean value was 5.09 , the test value or neutral point value $=4, \mathrm{p}=.00$ and $\mathrm{t}=68.98$. This indicates rejection of the null hypothesis. Familiarity with the medication does have a significant effect on patient's intent the request medications.

This finding is not consistent to previous literature by Katen (2004, p. 14). Traditionally, pharmaceutical companies have ignored consumer marketing during the pre-launch phase, spend large promotional budget at product launch and maintained reach and frequency through the maturity phase. However, the Pharmaceutical companies do not market to the patient once the medication faces patent expiration. This leads to a decrease in loyalty. Furthermore, Katen (2004, p. 14) explains that patient today expect products that are newer and better and quick succession. Customer education on newer therapies is replacing customer loyalty.

H5: There is a significant relationship between demographic factor and the patient's intent to request medication.

Five demographic factors were measured: (1) patient's gender, (2) patient's income, (3) patient's age, (4) patients education, and (5) employment status

\section{Patient Demographics}

1. Patient gender: A difference in means test was used. The independent sample test showed no difference between men and women and the intent to request medications, $t=1.199$ and $p$ $=.232$.

2. Patient's income: One-way ANOVA was used. Income has influence on patient's intent to request medication, $\mathrm{F}=.384$ and $\mathrm{p}=.536$. These results are due to perhaps to the intent to request medication variable low variance.

3. Patient's age: A One-way ANOVA was used. Income: One-way ANOVA was used. No statistically significant relationships were found between patient's age and the request from medication $\mathrm{F}=1.942$ and $\mathrm{p}=.165$.

4. Patient's education level: A One-way ANOVA was used. Education had a significant relationship regarding the request for medication $\mathrm{F}=1.695$ and $\mathrm{p}=.195$. 
5. Patient employment status. One-way ANOVA indicated that patient employment did not have a relationship regarding requesting medications

$\mathrm{F}=1.051$ and $\mathrm{p}=.307$

H6: There is a significant direct relationship between direct-to-consumer advertising and the patient's intent to request prescription drugs.

The meaning of the word relationship in this context is that there is an agreement with a questionnaire statement rather than a correlation. Hypothesis 6. The majority of responses were high the mean. The mean value was 4.64 , the test value $=4, p=.101$ and $t=1.648$. This indicates rejection of the null hypothesis. DTC does have a significant effect on patient's intent to request medication. This finding is not consistent with previous research by Alperstein and Peyrot (1993, p. 50). Seventy percent of the respondent in Alperstein objected to DTCA, 28\% felt it would confuse consumers, $21 \%$ that asking for an advertised product would upset a doctor, and $12 \%$ that DTCA would weaken the doctor-patient relationship. Calla L. Hogue (May, 2009) this study examined the effects of direct-to-consumer pharmaceutical advertising on the medical conversation occurring between doctors and their patients. Specifically, it analyzed the perceptions of physicians with regard to their experiences with patients who are exposed to media drug promotion. The study examined the perceptions to find emerging themes as a result of the impact of direct-to-consumer advertising influence on the medical dialogue between doctor and patient. The researcher suggests research that may provide further understanding of the health outcome of patients influenced by direct-to-consumer pharmaceutical advertising.

H7: There is a significant relationship between the formulary status of the medication and the patient's intent to request prescription drugs.

The meaning of the word relationship in this context is that there is an agreement with a questionnaire statement rather than a correlation. A sample mean test was utilized to test hypothesis 7 . The majority of responses were high the mean. The mean value was 5.33 , the test value $=4, p=.00$ and $t=68.98$. This indicates rejection of the null hypothesis. The formulary status of the medication is a significant factor in patient's intent to prescribe medication. Not much literature was found on the managed care influence on prescribing. According to Raisch (1990b), formularies were designed to influence prescribing, yet little was known about prescribing in managed care setting and their influence on the prescribing decisions. The study was tested on patients who suffered from different health condition. There was not enough variance in the intent to request medication variable since the majority of patients (75\%) agreed, slightly agreed or strongly agree that they would request medications to their physician. Patients want medication from their physicians when they walk in the doctor's offices or hospital. The study found that patients with higher education levels such as college degree, master level patients, tend to request more medications from their physicians.

Familiarity with the medication did not lead to patient's request for the same medication. This researcher explains that the pharmaceutical companies ignore consumer marketing during the post-launch phase of the product. Companies spend large budgets during the pre-launch of a product. However, companies leave consumers and their marketing efforts as the brand faces patent expiration. The research concludes that customers expect products that are newer and better and in quick succession.

Price of the medication is a strong factor when requesting medication to the physician. The majority of the patients in the study strong agree that price was a very important factor when 
deciding what medication to request to their physicians. The price of the medication includes the co-payment fee that the patient has to pay at the pharmacy. While imports of ethical drugs are approaching pre-crisis level again, the market remains dominate by generics, the need for which will be fuelled by cost-containment factors. Demand for healthcare services increased with the October 2001 introduction of a universal healthcare programme, known as the Bt30 scheme. Under scheme, even uninsured patients may visit any government hospital and play only Bt30 (US\$0.78) per visit, with the remaining cost of treatment borne by the government. The scheme covers most basic disease, as well as surgery and expensive treatment such as those for HIV/AIDS and cancer. An estimated 80\% of the Thai population benefits from the plan, with the government.

Hoping that in the long term universal healthcare coverage can be achieved throughout the country.

This study found that direct - to - consumer advertising have a significant effect on patient's request for medication and the effects of direct-to-consumer pharmaceutical advertising on the medical occurring between doctors and their patients. Specifically, it analyzed the perceptions of physicians with regard to their experiences with patients who are exposed to media drug promotion. The study examined the perceptions to find emerging themes as a result of the impact of direct-to-consumer advertising influence on the drugs. That mean why the pharmaceutical industry should be try to make marketing activities to promote to direct -tocustomer via any channels of advertising to attach their patients target.

\section{SUMMARY}

The finding of the study indicated that the study is useful for pharmaceutical industry in Thailand the variables that influenced prescription pattern of patients in Thai healthcare system. The study of factors influenced patients in Bangkok and greater Thailand were found that patient's want medication from their physicians when they walk in the doctor's office or hospital and patients with higher education level to request more medications from their physicians. Price of medication was a strong factor when patients request medications from their physicians. Direct-to-consumer advertising had a significant effect on patient's request for medication. In Thailand pharmaceutical industry tried to shift promotional program from physicians direct to patients.

Medicine today is not what is used to be a decade ago. Manny more channels are influencing the prescribing of medication in the pharmaceutical industry. These elements need to be consider when preparation of marketing efforts. Demographic factors such as education level and income different among patients and their request for medications. Most patients want medications regardless of their health condition; however this request is not conducive to a positive communication between patients and physicians. Therefore, communication channels between patients and physicians are to be implemented to allow patients to freely explore their choice of therapy. The key to successful healthcare communication is not what promotion vehicles are used but how to use them across the life of a pharmaceutical product. In essence, the patient is not just about compliance with a prescribed therapy; it is about driving the appropriate use of pharmaceutical therapy over the lifetime of an individual.

\section{DISCUSSIONS}

The objective of this investigation will demonstrate how pharmaceutical markets cares can use these factors to better market pharmaceutical products: (a) measure the impact of their current marketing campaigns in term of what is leading to increase and decrease in market share, (b) manage marketing to maximize impact to increase market share and ROI, (c) predict market share direction with better accuracy, and (d) understand how to connect marketing 
activities to corporate goals effectively. Pharmaceutical marketing terms and/or health care managers should identify the most effective media for communicating drugs therapy information for their organization and use these media to communicate message about preferred and non-preferred drugs to their prescribers. These managers should also understand the variables that influence the patient to request drugs and which communication vehicles are being used. This will ensure that their organization's preferred drugs are maintained within the physician's evoked set. Finally managers can use the most effective communication channel to target practice sites or individuals where adoption of a drug therapy innovation may be care readily accepted, after it can be diffused into the broader medical community.

\section{MANAGEMENT IMPLICATIONS AND RECOMMENDATIONS}

Pharmaceutical companies may have to restructure their operations to better serve their customers (patients and physicians), not just sell their products. Pharmaceutical companies must consider alternate promotion efforts. The pharmaceutical industry spends large quantities of money on the promotion of new products/treatment: direct-to-consumer advertising (television advertising, magazines, medical literature in physician offices, radio advertising, web sources, and internet etc). In the study direct-to-consumer advertising (DTC) was neutral an influential factors on physician prescribing. Direct-to-consumer advertising may help the patient in his/her journey for treatment options, but these efforts was leading to a positive response from physicians to prescribe more of the request drug. The presents a need for marketers to find other alternatives to promote their messages select appropriate market segments and target resources accordingly. Perhaps marketing efforts may include patient literature on therapeutic options and current treatments for specific health conditions. This may enhance communication and may assist the physician in his/her discussion about treatment option with patients.

Another important implication of this research is for pharmaceutical companies to pursue an integration of the marketing process that may enhance the synergy and communication between all parties. The pharmaceutical companies, the physicians and patients can interact in ways that look like a partnership rather than a vendor-customer relationship. For example, pharmaceutical companies can set a schedule for personal selling to physicians and synchronizing it with the timing of direct-to-consumer advertising campaigns.

\section{REFERENCES:}

Agrawal, M. (1999). Global competitiveness in the pharmaceutical industry: The effect of national regulatory, economic and market factors. New York: Pharmaceutical Products Press Haworth Press.

Alperstein, N. M., \& Peyrot, M. (1993). Consumer awareness of rescription drug advertising. Journal of Advertising Research, 4, 50-56.

American Medical Association Online. (2004). Ethics Journal of the American Medical Association. Retrived January 21, 2004, from http://www .ama-assn.org

Bates, A. (2003). Marketing to win market share: The role of doctor sentiment and benchmarking. International Journal of Medical Marketing, 3(2), 144-145.

Bell, R. A., Kravitz, R. L., \& Wilkes, M. S. (1999). Ten years of direct-to-consumer prescription drug advertising. American Journal of Law and Medicine, 25(1), 149-167.

Business Monitor International (2006). Thailand Pharmaceutical and Healthcare Report Q4, 5-54.

Calla L. Hogue (May, 2009). The impact of direct-to-consumer pharmaceutical advertising on the physician/patient conversation. South Dakota State University. Thesis Abstracts International. (UMI No. 1471061) 
Carolyn, S. (2004). Factors influencing prescribing in the pharmaceutical industry: Patients and physicians intent. Nova Southeastern University, USA. Dissertation Abstracts International, 59(10), 3890-A. (UMI No. 3144712)

Coleman, J. S., Katz, E., \& Menzel, H. (1996). Medical innovation, diffusion study.

New York: n.p.

Denig, P., Haaijer-Ruskamp, F. M., Wesseling, H., \& Versluis, A. (1991). Impact of clinical trials on the adoption of new drugs within a university hospital. European Journal of Clinical Pharmacology, 41(2), 325-328.

Findlay, S. (2002). Do ads really drive pharmaceutical sales?. Marketing Health Services, 38, 79-92.

Gonul, F. F., Carter, F., Petrova, E., \& Srinivasan, K. (2001, July). Promotion of prescription drugs and its impact on physicians' choice behavior. Journal of Marketing, 65(3), 79-92.

IMS Health. (2006). IMS health report global pharmaceutical market. Bangkok,

Thailand: Author.

IMS Health Quarterly Market Brief. (2006). Top 10 Pharmaceutical Companies in Thailand. Bangkok, Thailand: Author.

Johnson, G. L., Arkalgud R. (2000). Patient-physician relationships in the information age. Marketing Health Services, Chicago, 20(1), 20-28.

Katen, K. (2004, April). Staying flexible. Executive Excellence, 21(4), 14-29.

Lipsky, M. S., \& Taylor, C. A. (1997). The opinions and experience of family physicians regarding direct-toconsumer advertising. Journal of Family Practice, 3180, 495-499.

Magazine Publishers of America. (1999). Magazines: A healthy diagnosis. Return on investment for DTC pharmaceutical advertising. A Study Measuring the Effectiveness of Allergy Advertising, 21300, 1-12.

Osgood, C. E., Suci, G. J., \& Tannenbaum, P. H. (1957). The measurement of meaning. Urbana: University of Illinois Press.

Park, J. S., and Grow, A. (2007). The Social Reality of Depression: DTC Advertising of Antidepressants and Perceptions of the Prevalence and Lifetime Risk of Depression. Journal of Business Ethics, DOI 10.1007/s10551007-9403-7.

Pharmaceutical Engineering, Country Profile. (2006, July). A look at the pharmaceutical industry in Thailand. The Office Journal of ISPE, 26(1), 1-8.

The Pharmaceutical Industry in Thailand. (2006, June). Royal Danish Embassy. Bangkok: Author.

Pharmaceutical Review. (2003). Attention deficit hyperactivity disorder (ADHD), Retrieved February 14, 2003, from http://www .pharmaceuticalreview.com

Protocare Sciences. (2001). No significant difference in the risk of diabetes mellitus during treatmentwith typical versus atypical. Antipsychotics, CA: Author.

Rogers, E., \& McKenna, S. D. (1993). Managing takeover: Learning disabilities and the cultural dimension. Journal of Managerial Psychology, 8(2), 3-10.

Royal Danish Embassy, Bangkok Danish Trade Council. (2006). Sector Overview the Pharmaceutical Industry in Thailand. Bangkok: Author.

Schnuer, J. (2001). DCT marketers eye ethic media. Advertising Age, 72(12), 39.

Segal, R., \& Wang, F. (1999). Influencing physicians prescribing. Pharmacy Practice Management Quarterly, 19(3), 30-50.

Thailand Pharmaceutical and Healthcare Report Q4. (2006, December). Part of BMI's Industry Survey \& Forecasts, Published. Bangkok: Business Monitor International.

Williams, A. (2001). Consolidation Revisited. Journal of Commercial Biotechnology, 8(2), 130-139. 